NASA Technical Memorandum 84654

\title{
EXPERIMENTAL AERODYNAMIC HEATING TO SIMULATED SHUTTLE TILES
}

DON E. AVERY, PATRICIA A. KERR, AND ALLAN R. WIETING

LIBRARY COPY

$\operatorname{OR} 271983$

LANGLEY RESEARCH CENTER LIBRARY, NASA HAMPTON, VIRGINIA 

EXPERIMENTAL AERODYNAMIC HEATING TO SIMULATED SHUTTLE TILES

\author{
Don E. Avery \\ Patricia A. Kerr \\ Allan R. Wieting \\ NASA Langley Research Center \\ Hampton, Virginia
}

\section{Abstract}

The heat transfer to simulated Shuttle thermal protection system tiles was investigated experimentally using a highly instrumented metallic thin wall tile arranged with other metal tiles in a staggered tile array. Cold-wall heating rate data for laminar and turbulent flow were obtained in the Langley 8-Foot High-Temperature Tunnel at a nominal Mach number of 7 , a nominal total temperature of $3300^{\circ} \mathrm{R}$, free-stream unit Reynolds number from $3.4 \times 10^{5}$ to $2.2 \times 10^{6}$ per foot, and free-stream dynamic pressure of 1.8 to 9.1 psia. Experimental data are presented to illustrate the effects of flow angularity and gap width on both local peak heating and overall heating loads.

\section{Nomenc lature}

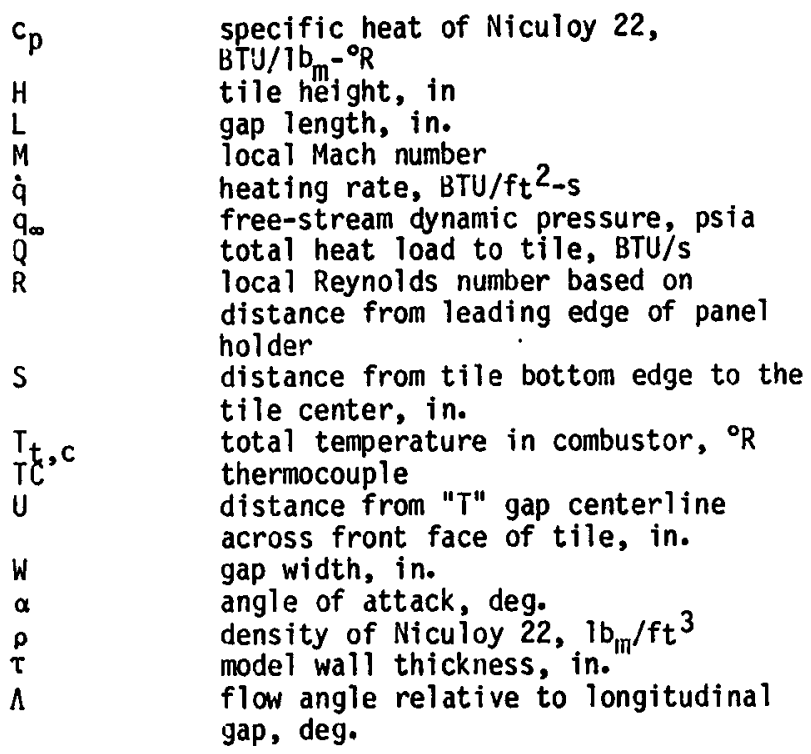

\section{Subscripts}

FP

flat plate

\section{Introduction}

The thermal protection system (TPS) of the Space Shuttle Orbiter 1 consists of silica-based reusable surface insulation (RSI) tiles. The tiles are applied to the surface with gaps between adjoining tiles to accommodate thermal and mechanical deflection of the underlying structure. These gaps locally disrupt the external boundary layer and, therefore, increase the aerodynamic heating during entry into Earth's atmosphere. To reduce the heating load, the tiles are arranged in a staggered pattern with the tile leading edges on the lower surface of the Shuttle swept $45^{\circ}$ relative to the Shuttle centerline. However, during atmospheric entry the local flow angle relative to the tile leading edge varies.

Previous aerothermal tests ${ }^{2-5}$ on simulated Shuttle type tiles provided a data base of localized and overall heating on the tiles. The localized heating affects the tile coating life while the overall heating affects the structural integrity of both tile and primary structure. From this data base, correlations for localized heating effects as influenced by boundary layer and gap geometry were developed. In reference 6 the data base for localized heating was extended with more detailed measurements and empirical relationships were developed that successfully predicted the effects of geometric and laminar and turbulent flow parameters on the localized heating in the "T" gap region for flow at $0^{\circ}$ relative to the gap. The "T" gap region is formed when a longitudinal gap terminates at its intersection with a tranverse gap. The present study further extends the data base to include the effect of flow angularity on localized and overall heating in both the "T" gap region and the upstreain corner. Flow angles tested include 0 , $15,30,45$, and 60 degrees. In addition, the effects of boundary layer state, Reynolds number, and gap width on localized and overall heating were investigated. Cold-wall heating rates were obtained in the Langley 8-Foot High-Temperature Tunnel at a nominal Mach number of 7 , a nominal total temperature of $3300^{\circ} \mathrm{R}$, free-stream unit Reynolds number from $3.4 \times 10^{5}$ to $2.2 \times 10^{6}$ per $\mathrm{ft}$. , and a free-stream dynamic pressure of 1.8 to 9.1 psia.

This report presents experimental data obtained in laminar and turbulent flow to illustrate the effects of flow angularity and gap width on both local peak heating and overall heating loads.

\section{Test Apparatus}

\section{Model Description}

The model used in this study consisted of a metallic tile array to simulate the resuable surface insulation (RSI) of the Space Shuttle's thermal protection system (TPS). Metallic tiles were used in lieu of RSI tiles because of their ease to handle and instrument: The tile material has no effect on the cold-wall heating rates at these test conditions. The 20 by 20 by $2.5 \mathrm{in}$. tile array (fig. 1) was basically the same array as 
used in reference 6 ; except, the 5.9 by $6.4 \mathrm{in}$. center tile was replaced with a highly instrumented tile, and the stainless-steel thin-wall tiles were not used to obtain data. The remaining tiles were solid aluminum blocks and all tiles had $0.10 \mathrm{in}$. edge radii. All the tiles were bolted to a

0.13-inch-thick stainless-steel plate and sealed to prevent flow under the tiles. Slotted bolt holes permitted adjustments of the tile positions to vary gap width with respect to the center tile. The gap widths, $W$, studied were $0.040,0.070,0.120$, and $0.160 \mathrm{in}$. with longitudinal and transverse gap widths equal. The longitudinal gap length, $L$, varied slightly as the gap width was varied but was essentially constant at $6 \mathrm{in}$. for all tests. The tile array was located in a turn table, that allowed the flow angle, $\Lambda$, to be varied to 0,15 , 30,45 , and 60 degrees with respect to the longitudinal gap. Nominal Shuttle tile dimensions are 6 by 6 by $2.5 \mathrm{in}$. and the gap width between the tiles is a nominal $0.045 \mathrm{in}$.

Conventional fabrication techniques used for the stainless-steel thin-wall tiles in reference 6 were not employed because (1) a high concentration of instrumentation in localized heating regions, the corners and edges were desired and (2) a uniform tile thickness along the tile corners and edges could not be achieved. Consequently, a new electrolessly plated nickel process was developed to fabricate the required highly responsive instrumented center tile which is shown schematically in figure 2 (rotated $90^{\circ}$ counter-clockwise relative to fig. 1). The process was an extension of techniques developed under a NASA Johnson Space Center contract to fabricate a small electrolessly plated nickel model with single-wire thermocouples. The small diameter $(0.005$ in.) single wire permits a higher concentration of instrumentation and reduction in thermal losses via the wire than can be obtained with standard two wire techniques. The new fabrication technique used six steps to produce a mandrel with 256 precisely located constantan thermocouple wires protruding from the mandrel. Niculoy 22 was then electrolessly plated over the mandrei to one-half the tile thickness $(0.0125$ in.). Before the final plating, the protruding thermocouple wires were clipped and polished smooth with the tile surface. A schematic of the instrumentation and a typical cross-section of a thermocouple junction is shown in the insert of figure 2. Finally, the mandrel was melted away leaving a free-standing thin-wall shell. As seen in figure 2 the thermocouples were located on all tile surfaces with concentrations in known localized high heating zones. The tile shell serves as the other thermocouple wire to complete the thermocouple circuit thereby forming a Niculoy $22 /$ constantan thermocouple. Since calibrations showed the thermoelectric properties of the Niculoy $22 /$ constantan to be very similar to copper/constantan, the properties of the latter were used to reduce the data.

\section{Panel Holder}

The model was mounted in a panel holder (fig. 3) which can accommodate test panels up to 42.5 by $60 \mathrm{in}$. (See refs. 8 and 9.) The aerodynamic surface ahead of the model consists of l-inch-thick low conductivity tiles and a $3 / 8$ inchthick steel plate. Aerodynamic fences provide uniform two-dimensional flow over the entire aerodynamic surface. A blunt leading edge with a radius of $0.374 \mathrm{in}$. is used on the panel holder to promote a laminar boundary layer, and a blunt or sharp leading edge with a lateral row of spherical boundary-layer trips (0.09 in. dia.) is used to produce a turbulent boundary layer over the aerodynamic surface of the panel holder. The center of the instrumented tile was located 61.1 in. from the blunt leading edge of the panel holder and 62.7 in. from the sharp leading edge of the panel holder.

\section{Test Facility}

The 8-Foot High-Temperature Tunnel (formerly 8-Foot High-Temperature Structures Tunnel; see fig. 4) is a large blowdown facility that simulates aerodynamic heating and pressure loading at a nominal Mach number of 7 and at altitudes between 80,000 and $130,000 \mathrm{ft}$. The high energy needed for this simulation is obtained by burning a mixture of methane and air under pressure in the combustor and expanding the products of combustion through a conical-contoured nozzle into the open jet test chamber. The flow enters a supersonic diffuser where the air ejector pumps the flow through a mixing tube and exhausts the flow to the atmosphere through a subsonic diffuser. This tunnel operates at combustor total temperatures between 2500 and $3600^{\circ} R$, free-stream dynamic pressure from 2.0 to $12.5 \mathrm{psia}$, and free-strean unit Reynolds numbers per foot from $0.3 \times 10^{6}$ to $3 \times 10^{6}$.

The model is stored in the pod below the test stream to protect it from adverse tunnel start-up transients and acoustic loads. Once the desired flow conditions are established, the model is inserted into the test stream on a hydraulically actuated elevator in approximately $1.5 \mathrm{~s}$ to approximate a step heat input to the model. A model pitch system provides an angle-of-attack range from $-20^{\circ}$ to $20^{\circ}$. More detailed information about the $8^{\prime}$ HTT can be found in references 8 and 9.

\section{Tests}

A total of 26 tests were conducted; eight were with laminar flow and 19 with turbulent flow. Table I outlines the tunnel flow conditions, and the corresponding panel holder and model geometry. The free-strean tunnel conditions were determined from temperatures and pressures measured in the combustor and are based on the thermal, transport, and flow properties of methane-air combustion products as reported in reference 10 and in the tunnel surveys of reference 9 .

The top surface of the instrumented tile was intended to be flush mounted with the other tiles for all tests; however, a post-test check indicated a nominal step height of $0.035 \mathrm{in}$. was present for test 19. The effect of this step height will be reported in the Results and Discussion section.

\section{Test Procedures}

The wind tunnel equilibrium flow conditions were established and then the model was inserted into the test stream. The model was pitched to the desired angle of attack before insertion into the test stream. The model was exposed to the flow approximately $2 \mathrm{~s}$ to avoid exceeding the $960^{\circ} \mathrm{R}$ temperature limit of the thin shell tile and to 
minimize thermal gradients and attendant thermal stresses.

\section{Data Reduction}

The tile heating response at the "T" gap indicated that the maximum heating rate occurred before the model reached the tunnel center line but after the panel holder was immersed in a core of uniform flow $48 \mathrm{in}$. in diameter. The cold-wall heating rates presented herein were taken at the time when the peak heating rate occurred in the " $T$ " gap (thermocouple 9). Thermocouple 9 was chosen as the reference because it reached the highest heating rate first.

Model and tunnel data were recorded by a highspeed digital recorder at 20 frames per $s$ through 10 hertz filters. Cold-wall heating rates were calculated from these outputs using the onedimensional transient heat balance equation $\left(\dot{q}=\rho \mathrm{C}_{\mathrm{p}} \tau(\mathrm{dT} / \mathrm{dt})\right)$, where $\mathrm{dT} / \mathrm{dt}$ was determined from a 5 poiht central difference approximation to smooth out noise in the data channels.

The one-dimensional heat balance equation equates the convective heat transfer to the surface to the energy stored with the effect of conduction and radiation assumed to be negligible. These assumptions are considered reasonable since the temperature-time slopes were taken early in the tests when the surface temperatures and spatial gradients were relatively low. In addition, analyses including lateral conduction and radiation effects indicated a maximum error of less than 17 percent in the heat flux in the " $T$ " gap region and approximately zero in all other areas.

The flat plate heating rates obtained from flat plate calibration tests $5,6,9$ were used to nondimensionalize the data. No calibration data existed for tests $9-16$, consequently, theoretica? values, which were in close agreement with extrapolated data from reference 9 were used. The flat plate total heat loads were obtained by multiplying the flat plate heating rate by the top surface area of the instrumented tile. These data are presented in Table II.

\section{Results and Discussion}

\section{Aerodynamic Heating in Laminar Flow}

Tests were conducted under laminar flow conditions to identify overall and local flow characteristics and to determine the effects of gap geometry on the magnitude and distribution of the convective heating in the " $T$ " gap region and on the upstream corner. All the laminar data were obtained at a nominal $T_{t, c}$ of $3100^{\circ} \mathrm{R}$, a nominal $q_{\infty}$ of 2.2 psia, and $\alpha=0^{\circ}$. In this section the stem of the " $T$ " will be defined as the longitudinal gap and the cap of the "T" will be defined as the transverse gap.

Effects of gap geometry on localized heating. Typical aerodynamic heating rate distributions on the upstream corner and the " $T$ " gap are characterized for laminar flow in figure 5 for $\Lambda=45^{\circ}$, and $W=0.070 \mathrm{in}$. The heating rates up the edge at the corner and side 1 at the "T" gap region and along the top surface to the tile center are nondimensionalized by the flat plate heating rate.
The heating rates are less than 20 percent of $\dot{q}_{F P}$ over the bottom 90 percent $(S / H<0.9)$ of the tile height and are within the accuracy of the measurement technique. In addition, the results indicate the laminar boundary layer does not readily penetrate the gaps. At a S/H of approximately 0.9 the heating rates increase rapidly and peak at approximately 1.5 times the flat plate value just behind the tile edge radius for these test conditions. Apparently, the flow bridges the gap to reattch on the top surface for this case. From this reattachment point the heating decreases to the flat plate value.

Previous results ${ }^{6}$ at $\Lambda=0^{\circ}$ also indicated that the maximum heating rate occurred on the top edge radius or just behind the edge in laminar flow. Herein, thermocouples 1 and 9 were chosen to represent the heating characteristics in the corner and " $T$ " gap regions, respectively. Thermocouples 1 and 9 are located on the mid arc of the corresponding edge radii. Other thermocouples in these regions show similar trends.

The effects of flow angularity on the heating rates at the corner and " $T$ " gap are shown in figure 6 for $W=0.070$ in. The curves represent least square first order polynominal fits to the data. Because of the low energy content of the flow penetrating into the tile gaps, local heating rates are insensitive to flow angle changes from $0^{\circ}$ to $60^{\circ}$. In general, the heating at the " $T$ " gap is greater than at the corner. The heating increases slightly at the corner but remains relatively constant at the " $T$ " gap with increasing $\Lambda$.

The effect of gap width on heating rates at the corner and "T" gap are shown in figure 7 for $\Lambda=45^{\circ}$. The data indicate the local peak heating is not very sensitive to increases in the gap width. The heating at the corner and " $T$ " gap increase linearly with gap width and for these tests increases approximately 36 percent as the gap width was increased from $0.040 \mathrm{in}$. to $0.160 \mathrm{in}$. Previous studies ${ }^{6}$ at a flow angle of $0^{\circ}$ and with the forward facing tile wall sloped backward $15^{\circ}$ off vertical, indicate an increase in heating of 243 percent may occur as the gap width is increased from 0.040 to 0.160 inch for laminar flow as shown in the figure. The data from reference 6 is lower than the present data (for $W<0.130$ in.) because of the $15^{\circ}$ slope of the forward face as shown by the correlations of reference 6 . Data for $\Lambda=0^{\circ}$ and $45^{\circ}$ show a similar trend for $w<0.12$ in., but apparently for $\Lambda=0^{\circ}$ a critical $W$ exists at which the local heating increases dramatically.

Overall tile heating. Typical laminar heating distribution around the tile for $\Lambda=0^{\circ}$ (test 1 ) and $\Lambda=45^{\circ}$ (test 5) are graphically displayed in shades of gray in figure 8 . The exploded view of the tile shows the details on the hidden sidewalls. The gray scale below the figure relates the shades of gray to the absolute and nondinensionalized heating rate. The heating to the lower $1 / 2$ inch of the tile is not displayed because all the thernocouples below that point were damaged during the fabrication process. The representation of the tile heating in figure 8 (a) shows that the heating to the tile with a flow angle of $0^{\circ}$ is uniform over the top surface. Again the heat input to the sidewalls is low because of the low energy content of the flow in the gaps. With a flow angle of $45^{\circ}$ (fig. $8(\mathrm{~b})$ ) no significant changes in the 
heating distribution are seen thus indicating the insensitivity of the heating in laminar flow to changes in $\Lambda$. Note that there is no increase in heat ing to side 1 due to the upstream " $T$ " gap with flow angles of $0^{\circ}$ and $45^{\circ}$. This data substantiates previous findings where the laminar external flow which penetrates into the gaps appears to be basically two-dimensional with relatively low energy content.

The heating rates are numerically integrated over the tile surface to get the heat load attributed to each surface and the total heat load to the tile. Surface and total heat loads are given in Table II. The effect of flow angularity on the total heat load to the tile is shown graphically in figure 9 for $W=0.070 \mathrm{in}$. The total heat load is nondimensionalized by the total heat load for a flat plate. The total heat load to the tile remains relatively constant at an average of 27 percent above the flat plate value. It is important to note that the surface areas of the four sidewalls contribute 62 percent of the total surface area. This large surface area results in the increased total heat load to the tile over the flat plate value even though the heating rates are very low. For instance, at $\Lambda=45^{\circ}$ the total heat load to the tile is 1.21 times the equivalent flat plate heat load with approximately 95 percent of the heat load from the top surface and 26 percent from the sidewalls. At $\Lambda=60^{\circ}$ the total heating on the top surface has increased drarnatically (Table II) to produce a total heat load twice the flat plate load. This increase is due to an increase in surface heating not an increase of heating in the gaps. Since the heating is greater than laminar but less than turbulent levels, the flow is believed to be transitional.

The effect of $W$ is shown in figure 10 for a $\Lambda$ of $45^{\circ}$. The total heating appears to decrease as the gap width is increased from 0.040 to 0.160 inch. This trend reflects events happening to the top surface as the side wall heating is essentially constant. No great significance is placed on this trend due to the limited data and the deviation over the gap width range is within the accuracy of the measurement technique.

\section{Aerodynamic Heating in Turbulent Flow}

Tests were conducted under turbulent flow conditions to identify overall and local flow characteristics and to determine the magnitude and distribution of the convective heating in the " $T$ " gap region and on the upstream corner as affected by gap geometry. Turbulent heating data were collected with a nominal $T_{t, c}$ of $3200^{\circ} R$, a $q_{\infty}$ between 1.8 and $9.0 \mathrm{psia}$, and $\alpha=0^{\circ}$ or $7.5^{\circ}$. Data are presented for nominal $q_{\infty}$ of 2.2 and 3.5 psia. One test with a nominal step height of approximately 0.035 inch is presented at the end of this section.

Effect of gap geometry on localized heating. Typical aerodynamic heating distributions on the upstream corner and the " $T$ " gap are characterized for turbulent flow in figure 11 for $\Lambda=45^{\circ}$ and $W=0.070 \mathrm{in}$. The heating rates up the edge at the corner and side 1 at the " $T$ " gap region and along the top surface to the tile center are nondimensionalized by the flat plate heating rate. The heating was negligible over the bottom 90 percent $(S / H<0.9)$ of the face and approximately the same level as in the laminar tests. At $S / H=0.9$, heating increased very rapidly and peaked at the tangency point between the edge radius and the top surface. The corner heating peaked at twice the flat plate heating and the " $T$ " gap heating peaked at approximately 1.8 times the flat plate heating. At both locations the surface heating quickly returned to a uniform heating value approximately 1.2 times the flat plate value.

As in the results from reference 6 the maximum heating occurs somewhere on the edge radius. Herein, thermocouples 1 and 9 were chosen again to represent the maximum heating in the corner and " $T$ " gap regions, respectively. Thermocouples 1 and 9 are located on the mid arc of the corresponding edge radii. Other thermocouples in these regions show similar trends.

The effects of flow angularity on the heating rates at the corner and " $T$ " gap are shown in figure 12 for $W=0.070 \mathrm{in}$. Increasing the flow angle from $0^{\circ}$ to $60^{\circ}$ significantly reduces the high localized heating in the "T" gap region by decreasing the amount of flow in the longitudinal gap, thus decreasing the flow impinging in the "T" gap region. At a flow angle of $0^{\circ}$ the maximum heating in the " $T$ " gap region was 7.8 times the flat plate heating rate. The heating decreases rapidly with increasing flow angle to a minimum measured value of 1.7 times the flat plate heating at a flow angle between $30^{\circ}$ and $45^{\circ}$. The heating in the " $T$ " gap at $\Lambda=60^{\circ}$ has increased to approximately twice the qंFp. This increase in heating is attributed to increased flow in the transverse gap as the external flow becomes more closely aligned with the transverse gap. The results from reference 5 show significant increased heating for aligned tile arrays $\left(\Lambda=90^{\circ}\right)$. The corner heating is lowest for $\Lambda<30^{\circ}$ and reaches a peak value three times the flat plate heating rate at $\Lambda=60^{\circ}$. Similar to the "T" gap heating, the corner heating would probably continue to increase as $\Lambda$ exceeded $60^{\circ}$ because the continuous transverse gaps would allow significant entrained flow and attendant increased heating at the corner and on the sidewails. The data suggest orienting the tile such that the local flow angle is between $30^{\circ}$ and $50^{\circ}$ to minimize the high localized heating. The baseline Shuttle orientation of $45^{\circ}$ therefore provides some margin to accommodate local $\Lambda$ changes during entry.

Previous studies ${ }^{6}$ for turbulent flow with $\Lambda=0^{\circ}$ indicate the peak heating in the " $T$ " gap increases with approximately the 0.4 power of the gap width. However, the present turbulent data at $\Lambda=45^{\circ}$ indicates ( $\mathrm{fig} .13$ ) heating in the corner and " $T$ " gap region decreases with increasing gap width. This trend is supported by data obtained at other test conditions and locations on the tile; however, this trend cannot be explained until more detailed analysis can be completed.

Overall tile heating. Typical turbulent heating distribution around a tile for $\Lambda=0^{\circ}$ (test 17) and $\Lambda=45^{\circ}$ (test 23) are graphically displayed in shades of gray in figure 14. The exploded view of the tile shows the details on the hidden sidewalls. The gray scale below the figures relates the shades of gray to the absolute and nondimensionalized heating rate. The scales are different in order to show the heating details. The high localized heating regions occur over a small area; therefore, all heating rates above 
$20 \mathrm{BTU} / \mathrm{ft}^{2}-\mathrm{s}$ are assigned to white. The heating to the lower $1 / 2$ inch of the tile is not displayed because all the thermocouples below that point were damaged during the tile fabrication process. For $\Lambda=0^{\circ}$, fig. $14(\mathrm{a})$, the heating on the top surface is generally uniform except along the edge where the top surface and side 1 intersect. This further illustrates the high flux gradients shown in figure 11. Apparently, the high heating is concentrated to such small areas that it has a minimal effect on overall heat load. The increased heating contours for the side walls indicate that the turbulent flow penetrates further into the gaps and has a higher energy content than laminar flow. The highest localized heating ( 7.8 times $\left.\dot{q}_{F p}\right)$ occurred at the center of the front face at the end of the " $T$ " gap for $\Lambda=0$. The high heating to the right of the "T" gap was caused by a slight tile misalignment. The misalignment (detected after the test) resulted in a forward facing step $0.010 \mathrm{in}$. since the tile upstream of the instrumented tile was depressed. The significant heating difference on either side of the " $T$ " gap illustrates the sensitivity of the heating to slight misalignments. The left and right sidewalls show evidence of deeper flow penetration into the gaps as the flow moves along a side (longitudinal) gap. At a flow angle of $45^{\circ}$ (fig. 14(b)) the high localized heating to the "T" gap is significantly less than the $\Lambda=0^{\circ}$ and the overall heating levels also decreased.

As for laminar flow tests, the local heating rates were numerically integrated over each surface to obtain total heat loads. The results are presented in Table II. The effect of flow angularity on the total heat load to the tile is shown in figure 15 for $W=0.070$ in. At $\Lambda=0^{\circ}$, the total heat load to the tile is 1.85 times the heat load to the equivalent flat plate area. The top surface heat load is 1.49 times the heat load to a smooth surface, and the total heat load to the 4 sidewalls is 0.36 times QFP. In contrast, at $\Lambda=45^{\circ}$ the total heat load to the tile is 1.25 times the flat plate heat load, the heat load to the top surface is 1.14 times the flat plate, and the sidewalls are 0.11 times QFP. The total heat load as well as the heat load to the top and sidewalls, in general, decreases with increasing flow angle. However, as indicated in figure 12 for the "T" gap region, as the flow angle is increased the heating reaches a minimum between $\Lambda=30^{\circ}$ and $40^{\circ}$. As the flow angle is increased farther, more flow penetrates into the transverse gap increasing the side wall heating and therefore the total heat load. As stated earlier, this increase is supported by reference 5 where aligned tile arrays $\left(\Lambda=90^{\circ}\right)$ experienced a total heat load 40 percent higher than a staggered tile arrangement $\left(\Lambda=0^{\circ}\right)$. In general, rotating the tile about the surface normal decreases the heating to the tile, reduces the localized heating in the " $T$ " gap region, and hence reduces the flow in the gaps which reduces the total heat load.

The effect of gap width on the total heat load is shown in figure 16 for $\Lambda=45^{\circ}$. As indicated by the least square linear fit to the data, a slight decrease in total heat load occurs with increasing $W$ as was the case with laminar flow. This result was not expected but the localized heating region experienced the same effects at $\Lambda=45^{\circ}$.

Effect of forward facing step on heating. For test 19 the top surface of the instrumented tile was inadvertently installed higher than the surrounding tiles, producirg a nominal forward facing step of 0.035 in. (one-half the gap width). Also, the two tiles upstrean of the instrumented tile were not at exactly the same level; therefore, the heating on the instrumented tile was not symmetric. The forward facing step in turbulent flow and $\Lambda=0^{\circ}$, resulted in high heating along the entire top edge of side 1 instead of only the localized heating observed in the no step case. The heating distribution ac oss side 1 at varjous depths in the transverse ga, are shown in figure 17. The high localized hea:ing still exists in the "T" gap region and decreasel rapidly from this point to a relatively unifo $m$ level out to the vertical edges of the tile. The ratio of the heating due to the forward facilig step to the heating with no forward facing step shows the effect of a forward facing step on the ront face heating (fig. 18). At $U=0$ the heriting ratio is approximately 1 indicating little uffect on local "T" gap heating due to the step. However, the step permitted direct impingement of tlie external flow on the raised portion of the tile ind increased mass flow in the transverse gap, hence causing higher heating away from the " $T$ " gap regior and at greater depths. The maximum local ncrease in heating due to the step was 2.8 times the heating for a no step case and occurred near the tile corner.

\section{Concluding Remarks}

The heat transfer to simulated Shuttle thermal protection system tiles was investigated experimenwall tile arranged with other metal tiles in a staggered tile array. This tile arrangement results in longitudinal gaps terminating at intersections with transverse gaps ("T" gaps). The present study extends previods efforts to include the effect of the flow angularity on localized heating in the " $T$ " gap and ustream tile corner. Flow angles investigated include $0,15,30,45$, and 60 degrees. Cold-wall heati.ng rate data (calculated by using the thin wall technique) for laminar and turbulent flow were obtained in the Langley 8-Foot High-Temperature Tunnisl at a nominal Mach number of 7 , a nominal total temperature of $3300^{\circ} \mathrm{R}$, free-stream unit Reynolds nunber from $3.4 \times 10^{5}$ to $2.2 \times 106$ per foot, and a frise-stream dynamic pressure of 1.8 to 9.1 psia.

For a laminar external houndary layer, the overall heating data indicatr: that the gap flow is basically two-dimensional ancl the flow penetrating the gaps has a low energy cortent. In general, localized and total heating is insensitive to changes in gap width and flor angle. Increasing the gap width when the flow ingle is $45^{\circ}$ has a much less dramatic effect on heating than at a flow angle of $0^{\circ}$. The total heat load is approximately 21 percent greater than the equivalent flat plate heat load; however, this increase is caused by the increased surface area from the sidewalls.

For turbulent external boundary layers, higher energy flow penetrated deeper into the gaps creating higher localized heating at the corner and " $T$ " gap regions than for laminar flow. Increasing the flow angle with respect to the longitudinal gap significantly reduces the higi localized heating in the "T" gap region and moderately increases the localized heating at the cornar region. This data 
suggest orienting the tiles such that the local flow angle is between $30^{\circ}$ and $50^{\circ}$ to minimize the localized heating. Misalignments of the instrumented tile, producing a maxinum forward facing step of one-half the gap width, produced very high localized heating along the top edge of the front face, thus illustrating the sensitivity of the heating to surface misalignment. For a gap width of $0.070 \mathrm{in}$. the total heat load to the tile was as much as 85 percent greater than the heat load to the equivalent flat plate area. In general, rotating the tile about the surface normal decreases the heating to the tile, reduces the localized heating in the " $T$ " gap region and hence reduces the flow in the gaps which reduces total heat load.

\section{References}

1Emde, Wendal1 D.: Thermal Protection System for the Shuttle Orbiter. Bicentennial of Materials Progress, Volume 21 of National SAMPE Symposium and Exhibition, Soc. Advance. Mater. and Process. Eng., 1976, pp. 964-978.

2Brewer, R. A. ; Saydah, A. R. ; Nestler, D. E. ; and Florence, D. E.: Thermal Perforinance Evaluation of RSI Panel Gaps for Space Shuttle Orbiter. J. Spacecraft and Rockets, Vol. 10, No. 1, Jan. 1973, pp. 23-28.

${ }^{3}$ Christensen, H. E.; and Kipp, H. W.: Data Correlation and analysis of Arc Tunnel and Wind Tunnel Tests of RSI Joints and Gaps. Volume I Technical Report. NASA CR-134345, 1974.
4Dunavant, James C.; and Throckmorton, David A.: Aerodynamic Heat Transfer to RSI Tile Surfaces and Gap Intersections. J. Spacecraft : Rockets, Vol. 11. No. 6, June 1974, pp 437-440.

${ }^{5}$ Weinstein, Irving; Avery, Don E.: and Chapman, Andrew J.: Aerodynanic Heating to the Gaps and Surfaces of Simulated Reusable-Sur ace-Insulation Tile Arrays in Turbulent Flow at Mich 6.6. NASA TM $X-3225,1975$.

${ }^{6}$ Avery, Don E.: Aerodynamic Heat:ng in Gaps of Thermal Protection System Tile Arriys in Laminar and Turbulent Boundary Layers. NA: A TP-1187, 1978.

${ }^{7}$ Stalmach, C. J., Jr.: Developmelts in Convective Heat Transfer Models Featuring Seariless and Selected-Detail Surfaces, Employin! Electroless Plating. NASA CR-144364, 1975.

8Deveikis, William D.; Bruce, Waller E., Jr.; and Karns, John R.: Techniques for Aerothermal Tests of Large, Flightweight Thermal Protection Panels in Mach 7 Wind Tunnel. NASA TM X-7198:3, 1974.

${ }^{9}$ Deveikis, William D.; and Hunt, 1. Roane:

Loading and Heating of a Large Flar. Plate at Mach 7 in the Langley 8-Foot High-Temperature Structures Tunne]. NASA TN D-7275, 1973.

10Leyhe, E. W.; and Howell, R. R.: Calculation Procedure for Thermodynamic, Transjiort, and Flow Properties of the Combustion Products of a Hydrocarbon Fuel Mixture Burned in Air with Results for Ethylene-Air and Methane-Air M xtures. NASA TN D-914, 1962.

Table I Tunnel conditions and test parameters for tile array

\begin{tabular}{|c|c|c|c|c|c|c|c|c|c|}
\hline Test No. & Type of flow & $\mathrm{T}_{\mathrm{t}} \mathrm{c}$ & $\begin{array}{r}q_{\infty}, \\
\text { psia }\end{array}$ & $\begin{array}{c}\alpha, \\
\operatorname{deg}\end{array}$ & $M_{1}$ & $R$ & $\begin{array}{l}\text { Panel Holder } \\
\text { configuratioa } \\
\text { (ref. 6) }\end{array}$ & deg & $\begin{array}{l}W, \\
\text { in }\end{array}$ \\
\hline $\begin{array}{r}1 \\
2 \\
3 \\
4 \\
5 \\
6 \\
7 \\
8 \\
9 \\
10 \\
11 \\
12 \\
13 \\
14 \\
15 \\
16 \\
17 \\
18 \\
19 a \\
20 \\
21 \\
22 \\
23 \\
24 \\
25 \\
26\end{array}$ & $\begin{array}{l}\text { Laminar } \\
\text { Laminar } \\
\text { Laminar } \\
\text { Laminar } \\
\text { Laminar } \\
\text { Laminar } \\
\text { Laminar } \\
\text { Laminar } \\
\text { Turbulent } \\
\text { Turbulent } \\
\text { Turbulent } \\
\text { Turbulent } \\
\text { Turbulent } \\
\text { Turbulent } \\
\text { Turbulent } \\
\text { Turbulent } \\
\text { Turbulent } \\
\text { Turbulent } \\
\text { Turbulent } \\
\text { Turbulent } \\
\text { Turbulent } \\
\text { Turbulent } \\
\text { Turbulent } \\
\text { Turbulent } \\
\text { Turbulent } \\
\text { Turbulent }\end{array}$ & $\begin{array}{l}3090 \\
3130 \\
3040 \\
3110 \\
3130 \\
3130 \\
3180 \\
3280 \\
3320 \\
3330 \\
3350 \\
3320 \\
3340 \\
3360 \\
3410 \\
3250 \\
3080 \\
3110 \\
3380 \\
3260 \\
3260 \\
3320 \\
3190 \\
3140 \\
3350 \\
3170\end{array}$ & $\begin{array}{l}2.17 \\
2.15 \\
2.16 \\
2.17 \\
2.07 \\
2.07 \\
2.18 \\
2.19 \\
2.22 \\
2.22 \\
2.15 \\
2.22 \\
1.93 \\
1.82 \\
2.29 \\
2.20 \\
3.48 \\
8.74 \\
3.54 \\
3.64 \\
3.61 \\
3.49 \\
3.42 \\
3.32 \\
3.57 \\
9.03\end{array}$ & $\begin{array}{l}0.3 \\
0.3 \\
0.3 \\
0.3 \\
0.3 \\
0.3 \\
0.3 \\
0.3 \\
0.3 \\
0.3 \\
0.3 \\
0.3 \\
0.3 \\
0.3 \\
0.3 \\
0.3 \\
7.6 \\
7.6 \\
7.6 \\
7.6 \\
7.6 \\
7.6 \\
7.6 \\
7.6 \\
7.5 \\
0.3\end{array}$ & $\begin{array}{l}3.2 \\
3.2 \\
3.2 \\
3.2 \\
3.2 \\
3.2 \\
3.2 \\
3.2 \\
3.2 \\
3.2 \\
3.2 \\
3.2 \\
3.2 \\
3.2 \\
3.2 \\
3.2 \\
5.5 \\
5.4 \\
5.6 \\
5.6 \\
5.6 \\
5.7 \\
5.6 \\
5.6 \\
5.6 \\
6.5\end{array}$ & $\begin{array}{l}2.01 \times 10^{6} \\
2.06 \times 10^{6} \\
2.07 \times 10^{6} \\
2.10 \times 10^{6} \\
2.09 \times 10^{6} \\
2.09 \times 10^{6} \\
1.98 \times 10^{6} \\
1.79 \times 10^{6} \\
1.92 \times 10^{6} \\
1.91 \times 10^{6} \\
1.85 \times 10^{6} \\
1.92 \times 10^{6} \\
1.88 \times 10^{6} \\
1.87 \times 10^{6} \\
1.77 \times 10^{6} \\
1.86 \times 10^{6} \\
5.01 \times 10^{6} \\
1.17 \times 10^{7} \\
4.50 \times 10^{6} \\
4.83 \times 10^{6} \\
4.79 \times 10^{6} \\
4.70 \times 10^{6} \\
4.80 \times 10^{6} \\
4.81 \times 10^{6} \\
4.59 \times 10^{6} \\
7.67 \times 10^{6}\end{array}$ & $\begin{array}{l}\text { Blunt } \\
\text { Blunt } \\
\text { Blunt } \\
\text { Blunt } \\
\text { Blunt } \\
\text { Blunt } \\
\text { Blunt } \\
\text { Blunt } \\
\text { Blunt, Trip:; } \\
\text { Blunt, Trip: } \\
\text { Blunt, Trip'; } \\
\text { Blunt, Trip:: } \\
\text { Blunt, Trip: } \\
\text { Blunt, Trip:; } \\
\text { Blunt, Trip: } \\
\text { Blunt, Trip:; } \\
\text { Sharp, Trip:; } \\
\text { Sharp, Trip: } \\
\text { Sharp, Trip: } \\
\text { Sharp, Trip:; } \\
\text { Sharp, Trip: } \\
\text { Sharp, Trip: } \\
\text { Sharp, Trip:; } \\
\text { Sharp, Trips: } \\
\text { Sharp, Trip:; } \\
\text { Sharp, Trips: }\end{array}$ & $\begin{array}{l}0 \\
15 \\
30 \\
60 \\
45 \\
45 \\
45 \\
45 \\
45 \\
45 \\
45 \\
45 \\
60 \\
30 \\
15 \\
0 \\
0 \\
0 \\
0 \\
15 \\
30 \\
60 \\
45 \\
45 \\
0 \\
45\end{array}$ & $\begin{array}{l}0.070 \\
0.070 \\
0.070 \\
0.070 \\
0.070 \\
0.040 \\
0.120 \\
0.160 \\
0.160 \\
0.120 \\
0.040 \\
0.070 \\
0.070 \\
0.070 \\
0.070 \\
0.070 \\
0.070 \\
0.070 \\
0.070 \\
0.070 \\
0.070 \\
0.070 \\
0.070 \\
0.040 \\
0.070 \\
0.070\end{array}$ \\
\hline
\end{tabular}

a nominal step height of 0.035 in. 
Table II Total heat loads and flat plate heating rate

\begin{tabular}{|c|c|c|c|c|c|c|c|c|}
\hline Test No. & $\begin{array}{c}Q, \\
B T U / s\end{array}$ & $\begin{array}{l}\text { Qtop, } \\
\text { BTU/s }\end{array}$ & $\mathrm{Q}_{\text {Bide }} 1$, & $\underset{\text { BTU/s }}{Q_{\text {side }} 2,}$ & $\underset{\text { BTU/s }}{\text { Qside }} 3$, & $\begin{array}{c}\text { Qside } 4, \\
\text { BTU/s }\end{array}$ & $\underset{\text { BTU/s }}{\text { QFP, }}$ & $\underset{\text { BrU/ft }}{q^{2}-s}$ \\
\hline $\begin{array}{r}1 \\
2 \\
3 \\
4 \\
5 \\
6 \\
7 \\
8 \\
9 \\
10 \\
11 \\
12 \\
13 \\
14 \\
15 \\
16 \\
17 \\
18 \\
19 \\
20 \\
21 \\
22 \\
23 \\
24 \\
25 \\
26 \\
\end{array}$ & $\begin{array}{l}0.175 \\
0.224 \\
0.222 \\
0.323 \\
0.194 \\
0.259 \\
0.173 \\
0.216 \\
0.376 \\
0.484 \\
0.465 \\
0.423 \\
0.351 \\
0.414 \\
0.485 \\
0.350 \\
2.771 \\
4.682 \\
2.349 \\
2.197 \\
1.855 \\
1.931 \\
1.876 \\
1.963 \\
2.726 \\
2.204\end{array}$ & $\begin{array}{l}0.130 \\
0.176 \\
0.161 \\
0.257 \\
0.153 \\
0.204 \\
0.118 \\
0.167 \\
0.283 \\
0.386 \\
0.369 \\
0.350 \\
0.293 \\
0.331 \\
0.393 \\
0.194 \\
2.231 \\
3.687 \\
1.850 \\
1.834 \\
1.586 \\
1.740 \\
1.708 \\
1.790 \\
2.171 \\
1.834\end{array}$ & $\begin{array}{l}0.014 \\
0.013 \\
0.020 \\
0.025 \\
0.010 \\
0.018 \\
0.016 \\
0.016 \\
0.032 \\
0.027 \\
0.028 \\
0.027 \\
0.025 \\
0.027 \\
0.034 \\
0.054 \\
0.201 \\
0.422 \\
0.232 \\
0.086 \\
0.058 \\
0.074 \\
0.056 \\
0.050 \\
0.134 \\
0.106\end{array}$ & $\begin{array}{l}0.014 \\
0.013 \\
0.017 \\
0.020 \\
0.010 \\
0.016 \\
0.017 \\
0.014 \\
0.033 \\
0.025 \\
0.025 \\
0.015 \\
0.015 \\
0.017 \\
0.023 \\
0.046 \\
0.166 \\
0.227 \\
0.137 \\
0.136 \\
0.101 \\
0.033 \\
0.033 \\
0.041 \\
0.196 \\
0.129\end{array}$ & $\begin{array}{l}0.006 \\
0.011 \\
0.009 \\
0.008 \\
0.009 \\
0.009 \\
0.010 \\
0.010 \\
0.013 \\
0.026 \\
0.012 \\
0.011 \\
0.009 \\
0.015 \\
0.012 \\
0.017 \\
0.069 \\
0.147 \\
0.047 \\
0.031 \\
0.028 \\
0.041 \\
0.030 \\
0.027 \\
0.072 \\
0.050\end{array}$ & $\begin{array}{l}0.011 \\
0.010 \\
0.015 \\
0.013 \\
0.013 \\
0.012 \\
0.013 \\
0.009 \\
0.016 \\
0.019 \\
0.031 \\
0.021 \\
0.010 \\
0.024 \\
0.023 \\
0.039 \\
0.103 \\
0.200 \\
0.083 \\
0.111 \\
0.081 \\
0.043 \\
0.051 \\
0.055 \\
0.153 \\
0.085\end{array}$ & $\begin{array}{l}0.16 \\
0.16 \\
0.16 \\
0.16 \\
0.16 \\
0.16 \\
0.16 \\
0.16 \\
0.47 \\
0.47 \\
0.47 \\
0.47 \\
0.47 \\
0.47 \\
0.47 \\
0.47 \\
1.50 \\
1.58 \\
1.50 \\
1.50 \\
1.50 \\
1.50 \\
1.50 \\
1.50 \\
1.50 \\
1.58\end{array}$ & $\begin{array}{r}0.6 \\
0.6 \\
0.6 \\
0.6 \\
0.6 \\
0.6 \\
0.6 \\
0.6 \\
1.8 \\
1.8 \\
1.8 \\
1.8 \\
1.8 \\
1.8 \\
1.8 \\
1.8 \\
5.8 \\
12.0 \\
5.8 \\
5.8 \\
5.8 \\
5.8 \\
5.8 \\
5.8 \\
5.8 \\
6.1\end{array}$ \\
\hline
\end{tabular}

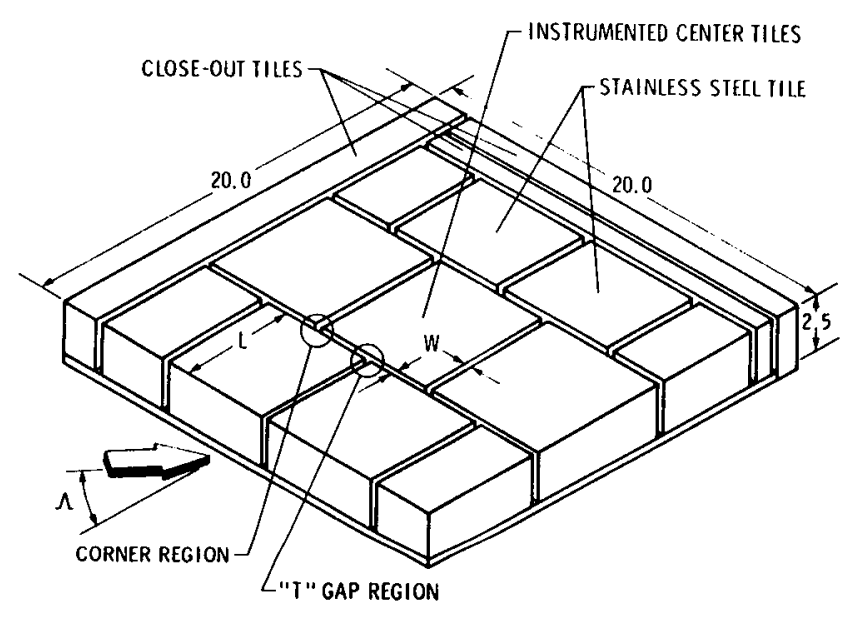

Fig. 1 Metallic tile array and test parameters. (Dimensions are in inches.)

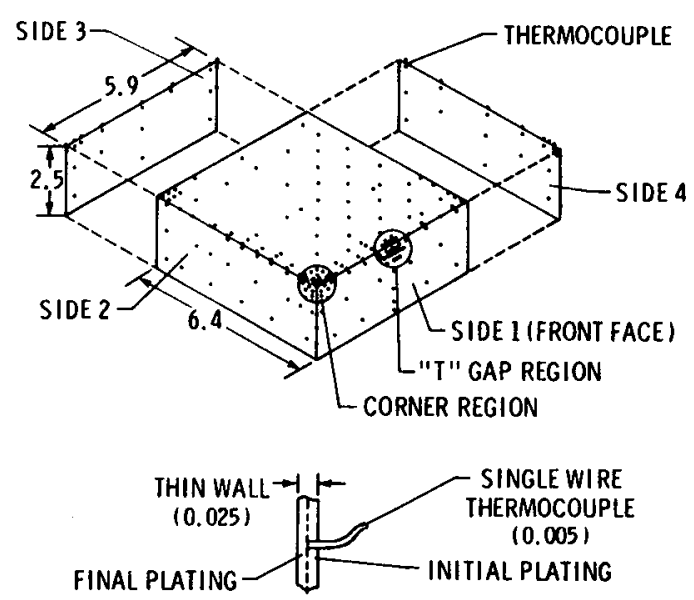

Fig. 2 Instrumented center tile and instrumentation detail. (Dimensions are in inches.) 


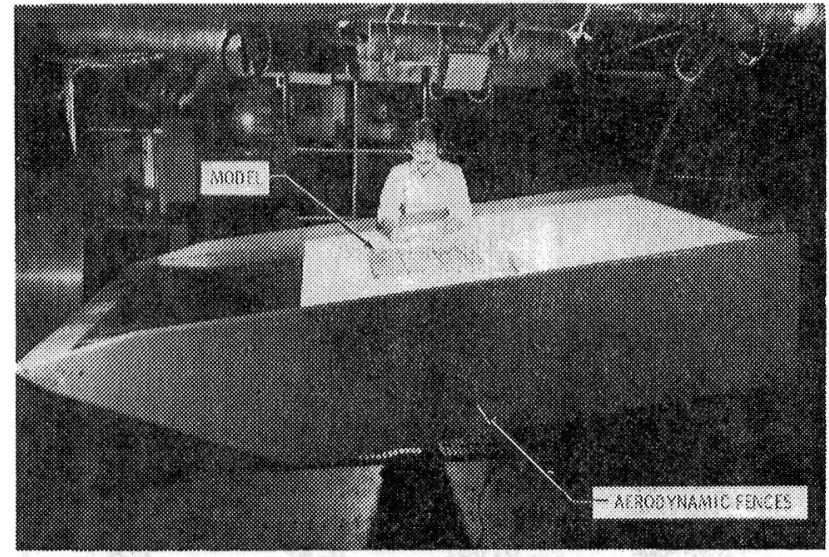

Fig. 3 Panel holder with gap heating model installed in 8-Foot High-Temperature Tunnel.

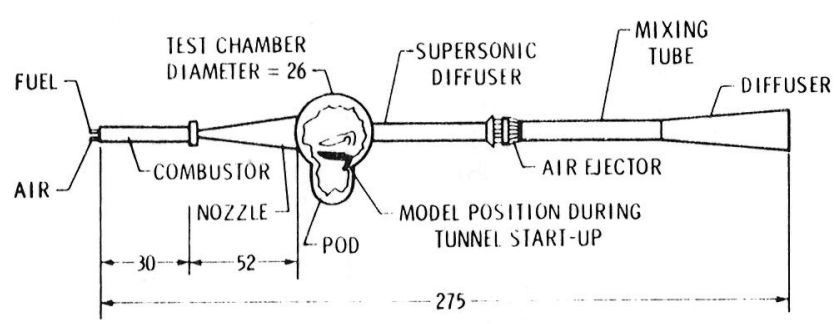

Fig. 4 Langley 8-Foot High-Temperature Tunnel. (Dimensions are in feet.)

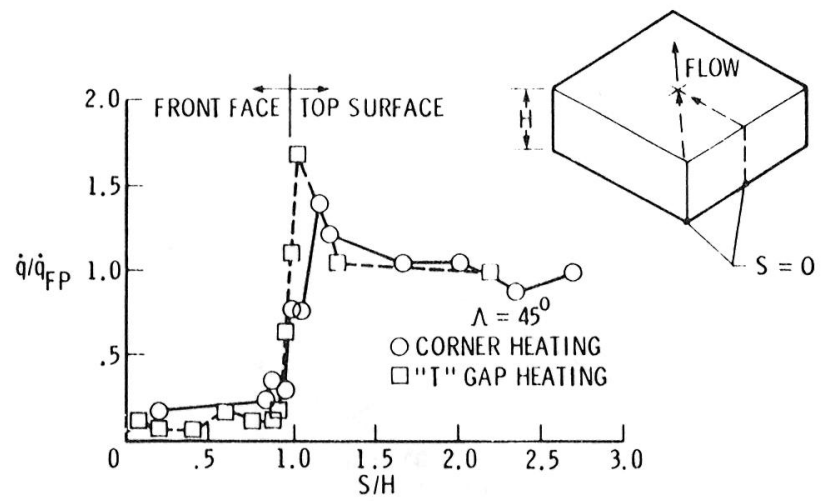

Fig. 5 Heating distributions from tile bottom to tile center at upstream corner and " $T$ " gap in laminar flow (test 5).

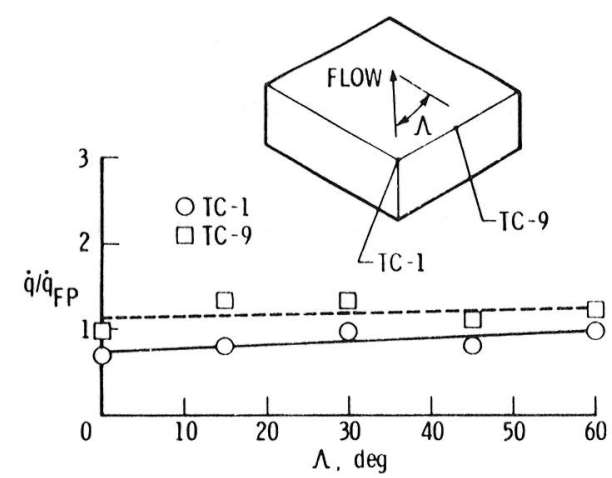

Fig. 6 Effect of flow angularity on corner and "T" gap heating in laminar flow $(w=0.070 \mathrm{in.})$.

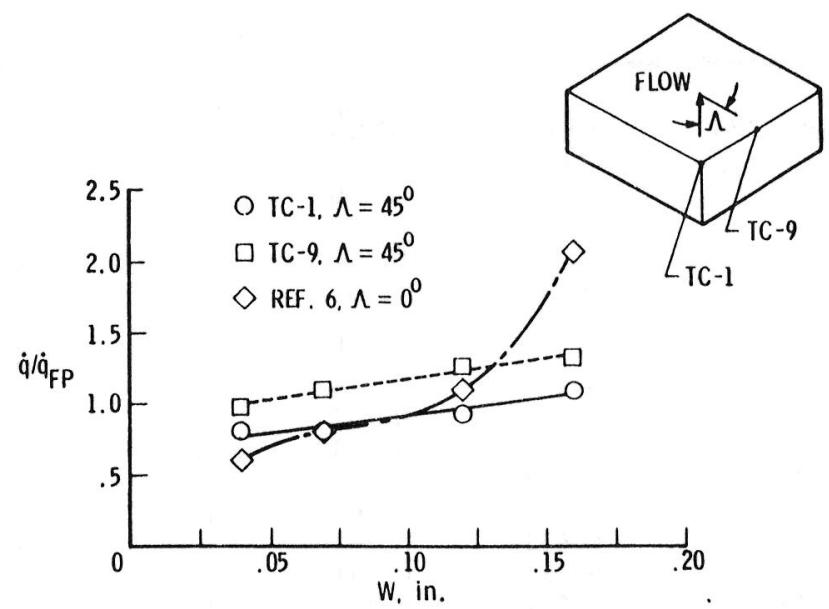

Fig. 7 Effect of gap width on corner and " $T$ " gap heating in laminar flow.

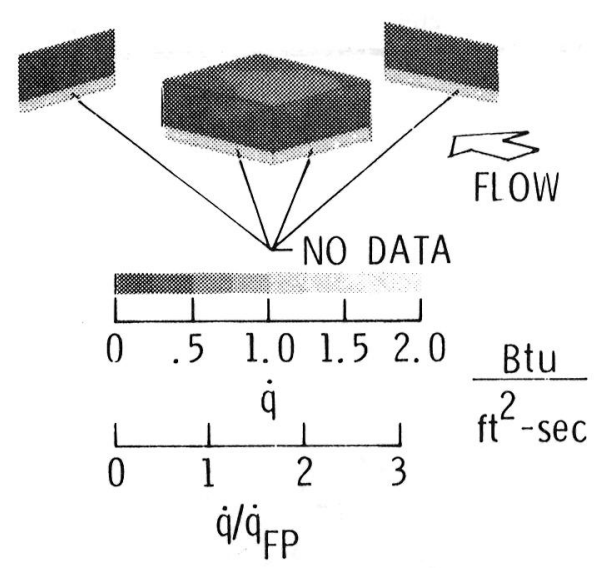

(a) Flow angle is $0^{\circ}$ (test 1 ).

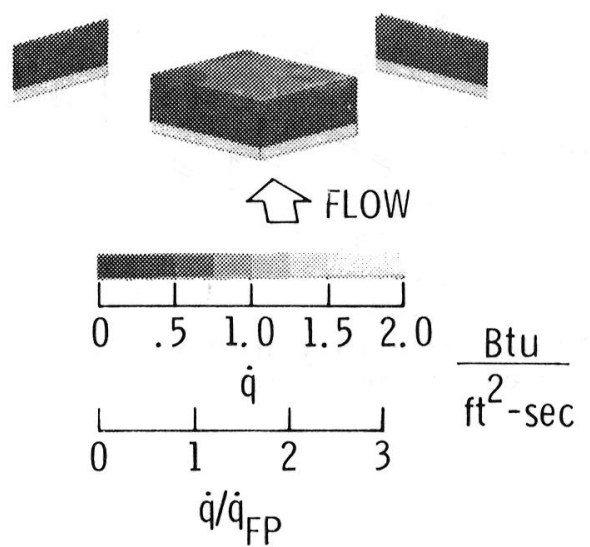

(b) Flow angle is $45^{\circ}$ (test 5 ).

Fig. 8 Overall heating distribution in laminar flow $\left(\dot{q}_{F P}=0.6 \mathrm{Btu} / \mathrm{ft}^{2}-\mathrm{s}\right)$. 


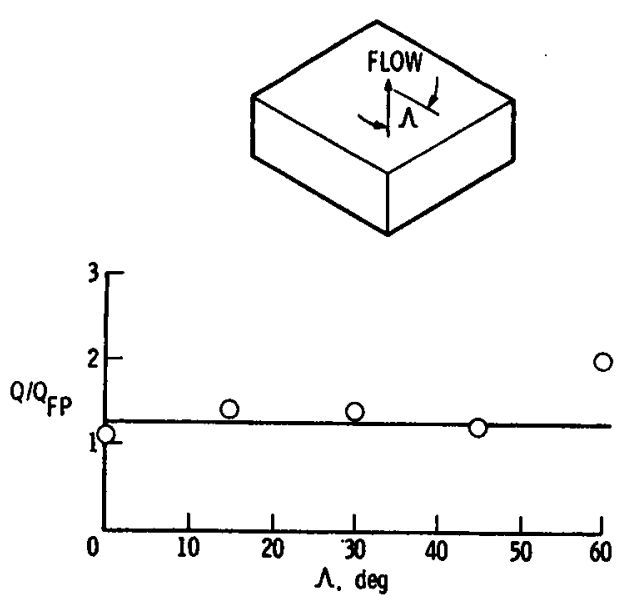

Fig. 9 Effect of flow angularity on total heat load in laminar flow $(W=0.070 \mathrm{in.})$.
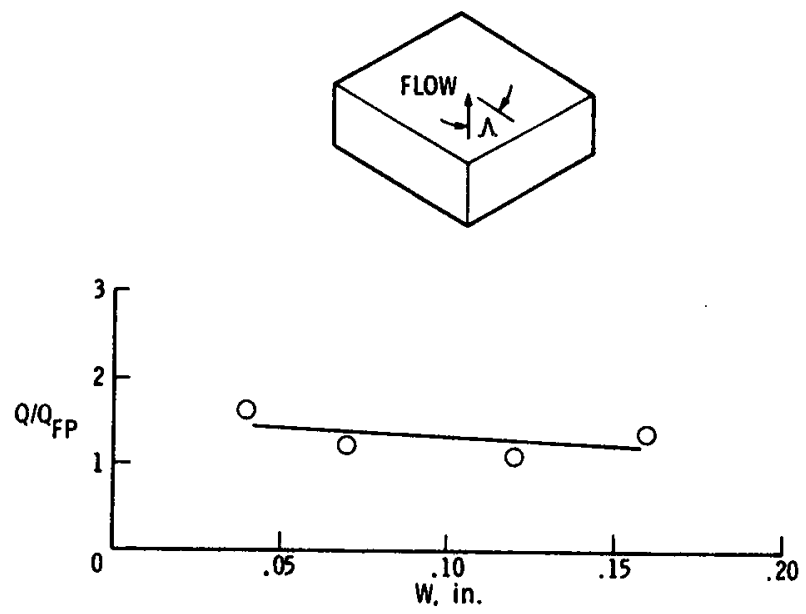

Fig. 10 Effect of gap width on total heat load in laminar flow $\left(\Lambda=45^{\circ}\right)$.

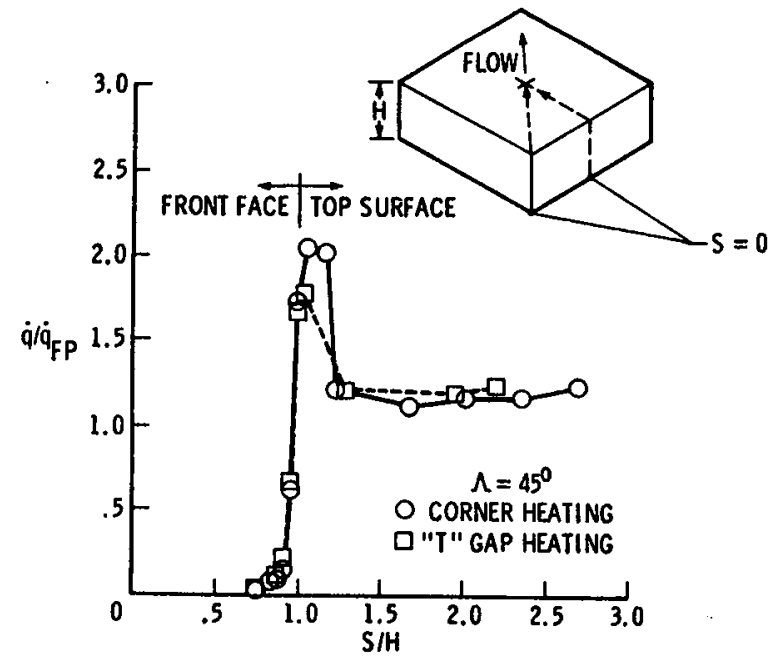

Fig. 11 Heating distributions from tile bottom to tile center at upstream corner and " $T$ " gap in turbulent flow (test 23).

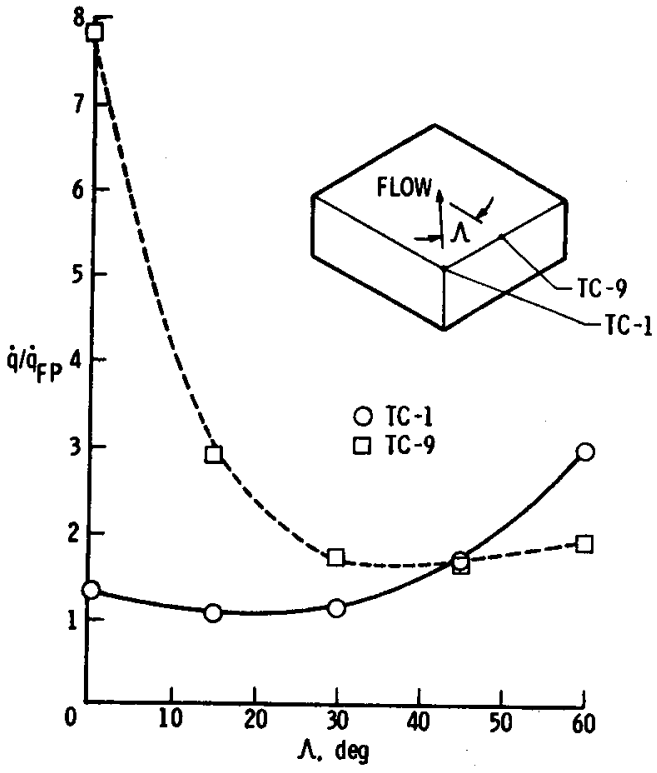

Fig. 12 Effect of flow angularity on corner and "T" gap heating in turbulent flow $(W=0.070 \mathrm{in}$.$) .$

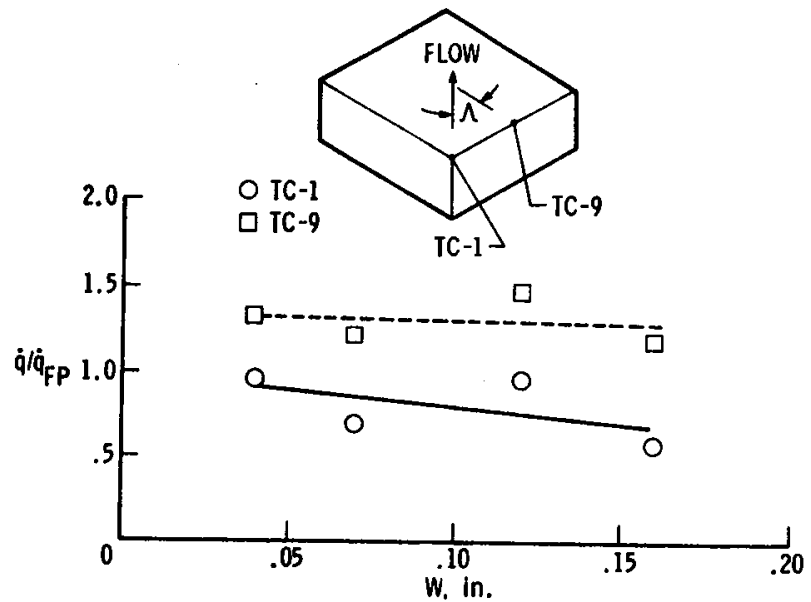

Fig. 13 Effect of gap width on corner and "T" gap heating in turbulent flow $\left(\Lambda=45^{\circ}\right)$. 


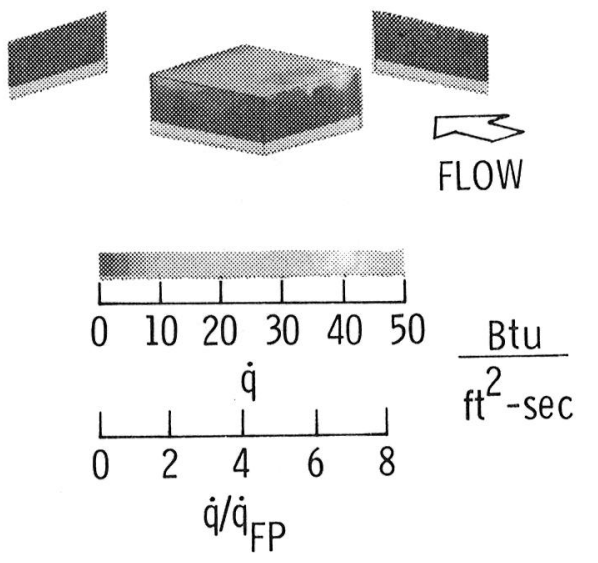

(a) Flow angle is $0^{0}$ (test 17).

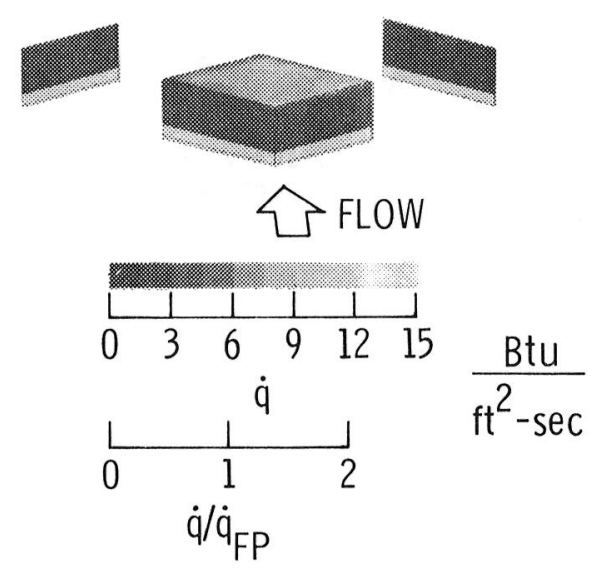

(b) Flow angle is $45^{\circ}$ (test 23).

Fig. 14 Overall heating distribution in turbulent flow $\left(\dot{q}_{F P}=5.8 \mathrm{Btu} / \mathrm{ft}^{2}-\mathrm{s}\right)$.

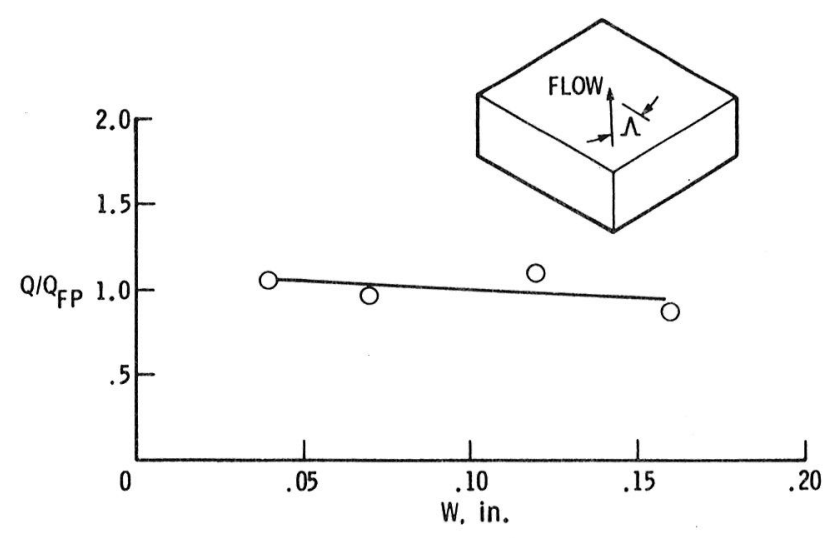

Fig. 16 Effect of gap width on total heat load in turbulent flow $\left(\Lambda=45^{\circ}\right)$.

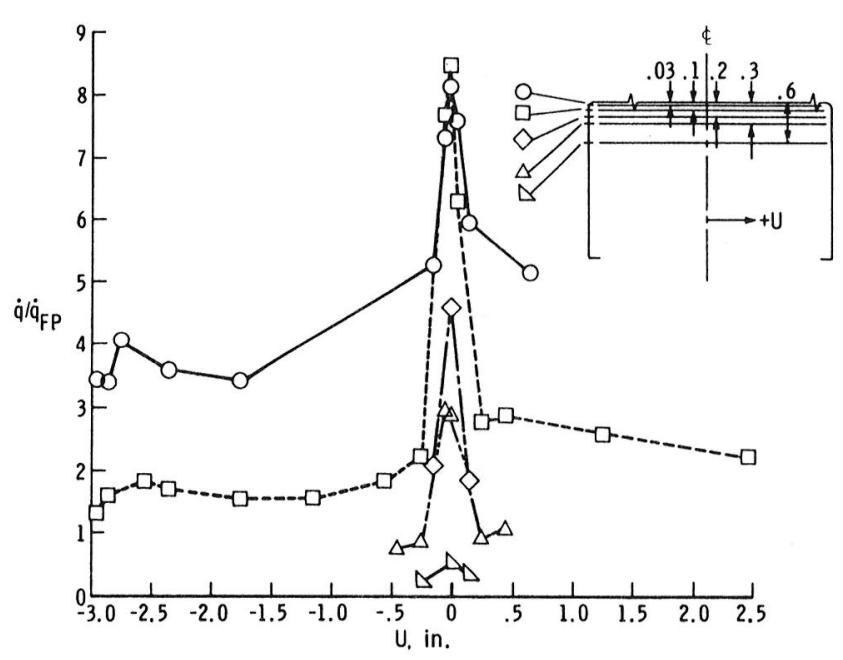

Fig. 17 Heating distribution across side 1 (front face) with a nominal step height of $0.035 \mathrm{in}$. (test 19).

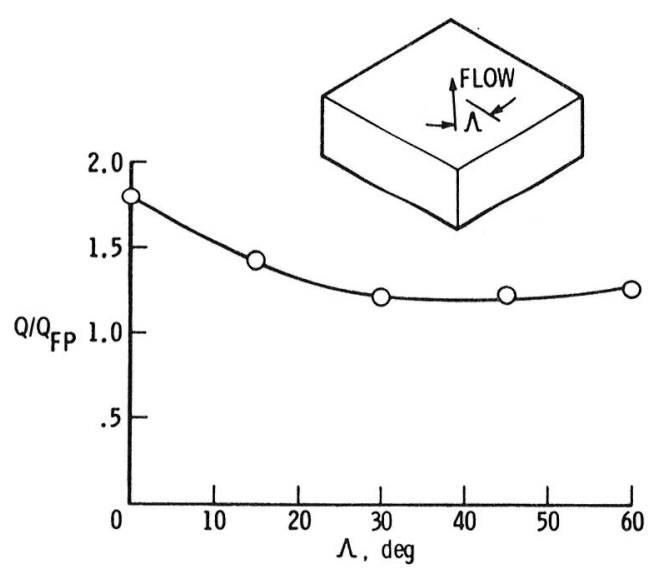

Fig. 15 Effect of flow angularity on total heating load in turbulent flow $(W=0.070$ in.).

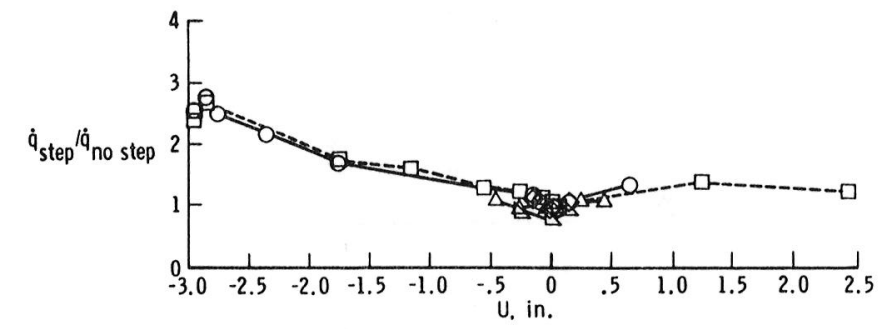

Fig. 18 Ratio of heating with step to heating with no step across side 1 (tests 19 and 17). 


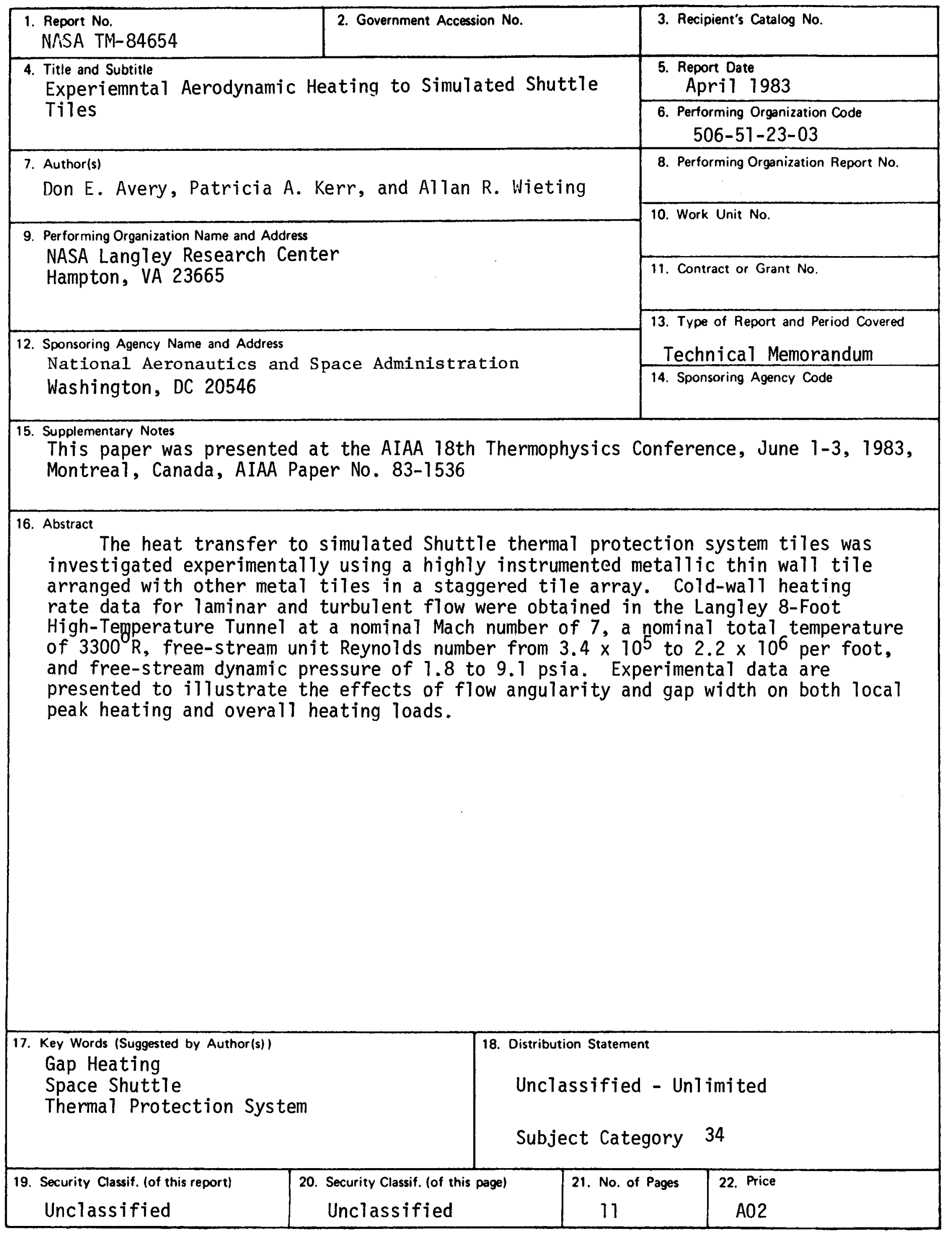




